\title{
Durability of joints made with threaded steel rods glued in chestnut timber - An experimental approach
}

\author{
E. Martín-Gutiérrez ${ }^{1}$, J. Estévez-Cimadevila ${ }^{1}$, D. Otero-Chans ${ }^{1}$ \\ (1) University of A Coruña, Department of Architectural, Civil and Aeronautical Building Structures, \\ Campus A Zapateira, 15071, A Coruña, Spain. \\ Corresponding author: emilio.martin@udc.es (Emilio Martín-Gutiérrez) \\ ORCID:https://orcid.org/0000-0001-7464-4288 (Emilio. Martín-Gutiérrez) \\ https://orcid.org/0000-0002-8460-2097 (Javier Estévez-Cimadevila) \\ https://orcid.org/0000-0003-1738-252X (Dolores Otero-Chans)
}

\begin{abstract}
This paper presents the results of an experimental study developed on joints made with glued-in rods in glued laminated chestnut, with the rods inserted parallel to the grain. Three anchor lengths have been used. The test pieces have been submitted to pullcompression test until failure after three different previous conditionings: preservation in a normalized atmosphere, artificial accelerated weathering cycles, and climate conditioning under uniform service load. The results indicate that the aging cycles lead to drops of stiffness and pull-out strength in the joints with usual anchorage lengths in practice. Therefore, there is not a significant difference in the value of those losses due to the action of the service load during the accelerated weathering cycles.
\end{abstract}

KEYWORDS: Wood; Strength; Mechanical testing; Joints/joining. 


\section{Introduction}

Glued-in steel rods have been used for the last decades to solve timber connections, both in new structural solutions and in rehabilitation and repair works [1-3]. Facing other traditional alternatives, they constitute a technique with a great potential. The hidden steel joints not only involve aesthetic improvements but they also offer protection against corrosion and are more fire-resistant. They allow the making of stiff joints with a great capacity of transmitting efforts and a notorious ductility. Therefore, they are versatile systems, with a minimum volume of intervention, easy manufacturing and application and reasonable costs.

Many studies have been developed to determinate, in an analytical and experimental way, the axial strength of this type of joints. The empirical expression suggested by Riberholt [4] is considered to be pioneer in this field. Being hybrid joints, formed by three materials, their behaviour has been researched by combining different types of timber, adhesive and bars [5-8].

Therefore, it has been analysed the influence of the different geometric parameters that are involved: anchorage length, bar diameter, adhesive thickness, proportions of the wooden piece, distance between close bars and to the edge of the piece [9-16]. The work made by Tlustochowicz et al. [17] constitutes a complete revision of the state of the art. The obtained results have allowed to catalogue the different forms of failure and formulate calculus expressions that present evident discrepancies concerning what is indicated in the Eurocode 5 [18]. Thereon, the comparisons of the design rules made by Stepinac et al. [19] and Ling et al. [20] are interesting.

Almost all the quoted studies pay attention to the behaviour of these joints in softwood. Our team has extended the research including hardwood species [21-23]. Particularly, we have worked with chestnut, a type of timber which is commonly used in the traditional construction in our geographical scope. In this way, it is aimed to improve these connections in the rehabilitation and restoration of historical buildings.

Even though it currently exists a wide knowledge about this topic, it becomes necessary to evaluate the behaviour of the glued-in rods along the service life of the construction. To that end it is essential to incorporate specific aspects such as long term loads, fatigue phenomena or the effects of weathering cycles $[11,18]$.

Aicher et al. [24] have developed the duration of load effect experiments (DOL) with threaded steel rods bonded in glulam under two different artificial climates. The results show that the connections with epoxy adhesives are rarely affected by weathering conditions, except for environmental temperatures over $50^{\circ} \mathrm{C}$, that cause significant strength losses.

Bainbridge et al. [1] also approach DOL tests in service class related conditions, with the specimens supporting $70-80 \%$ of the mean ultimate capacity in tension. The authors outline that the choice of the adhesive can have an impact upon failure mode and performance levels.

Custodio et al. [25] have analyzed the long-term durability of bonded timber joints, exposing loaded test specimens to natural or artificial accelerated weathering. They propose a realistic experimental methodology and move forward in the adjustment of the service life predictive models according to the observed results. 
Lartigau et al. [26] also prove that the durability of the repairs by glued-in rods is mainly dependent of the thermo-mechanical performance of the adhesive chosen.

Hunger et al. [27] have developed pull-compression tests under different climate conditions using two types of adhesives and several timber species.

Only the references [25] and [27] have included hardwood species. In the first one European oak (Quercus robur) was used with two types of epoxy adhesives, even though only with gluing lengths of $10 \mathrm{~mm}$. In the second reference tests of European beech (Fagus sylvatica) and European ash (Fraxinus excelsior) with two-component resins (epoxy and polyurethane) were tried using metric thread rods (M12, grade 8.8) with a bond line thickness of $2 \mathrm{~mm}$ and an anchorage length of $90 \mathrm{~mm}$.

In this paper, the behaviour of glued-in rods with chestnut timber, under climate conditioning is analyzed. The results are compared to the ones obtained by shortterm tests, under standard room conditions and without previous loads.

\section{Materials and methods}

\subsection{Materials}

All the specimens have been manufactured with glued laminated timber in chestnut (Castanea sativa). It has been used $32 \mathrm{~mm}$ sheets glued with amnioblast adhesive, meeting the performance requirements specified in the standard [28]. Table 1 gathers the properties provided by the manufacturer, according to [29].

Table 1. Properties of glued laminated chestnut

\begin{tabular}{lll}
\hline Bending strength $\left(\mathrm{N} / \mathrm{mm}^{2}\right)$ & $\mathrm{f}_{\mathrm{m}, \mathrm{g}, \mathrm{k}}$ & 30.0 \\
Tensile strength $\left(\mathrm{N} / \mathrm{mm}^{2}\right)$ & $\mathrm{f}_{\mathrm{t}, \mathrm{og}, \mathrm{k}}$ & 20.7 \\
& $\mathrm{f}_{\mathrm{t}, \mathrm{go}, \mathrm{g}, \mathrm{k}}$ & 0.7 \\
Compression strength $\left(\mathrm{N} / \mathrm{mm}^{2}\right)$ & $\mathrm{f}_{\mathrm{c}, \mathrm{o}, \mathrm{g}, \mathrm{k}}$ & $45 \cdot \mathrm{O}^{(1)}$ \\
Shear strength $\left(\mathrm{N} / \mathrm{mm}^{2}\right)$ & $\mathrm{f}_{\mathrm{c}, \mathrm{g}, \mathrm{g}, \mathrm{k}}$ & $5 \cdot 5$ \\
Rolling shear strength $\left(\mathrm{N} / \mathrm{mm}^{2}\right)$ & $\mathrm{f}_{\mathrm{v}, \mathrm{g}, \mathrm{k}}$ & 5.0 \\
Modulus of elasticity $\left(\mathrm{N} / \mathrm{mm}^{2}\right)$ & $\mathrm{f}_{\mathrm{r}, \mathrm{g}, \mathrm{k}}$ & 1.2 \\
& $\mathrm{E}_{\mathrm{o}, \mathrm{g}, \text { mean }}$ & 13000 \\
Shear modulus $\left(\mathrm{N} / \mathrm{mm}^{2}\right)$ & $\mathrm{E}_{\mathrm{go}, \mathrm{g}, \text { mean }}$ & 1400 \\
Rolling shear modulus $\left(\mathrm{N} / \mathrm{mm}^{2}\right)$ & $\mathrm{G}_{\mathrm{g}, \text { mean }}$ & 810 \\
Density $\left(\mathrm{kg} / \mathrm{m}^{3}\right)$ & $\mathrm{G}_{\mathrm{r}, \mathrm{g}, \text { mean }}$ & 65 \\
& $\rho_{\mathrm{g}, \mathrm{k}}$ & 520 \\
\hline
\end{tabular}

(1) Characteristics value for service class 1 . For service class 2 a reduction by $1 / 3$ applies

It has been determinate the relative density of every piece by the procedure which is described in [30]. Figure 1 shows the resultant distribution of densities, all of them between the interval $520-660 \mathrm{~kg} / \mathrm{m}^{3}$. The characteristic $\left(528.49 \mathrm{~kg} / \mathrm{m}^{3}\right)$ and mean $\left(583.47 \mathrm{~kg} / \mathrm{m}^{3}\right)$ values are placed above the previous specifications. 
Threaded bars of galvanized steel of quality 10.9 (ultimate tensile stress $f_{u}=1000$ $\mathrm{N} / \mathrm{mm}^{2}$; yield strength $\mathrm{f}_{\mathrm{y}}=900 \mathrm{~N} / \mathrm{mm}^{2}$ ) [31] were used as link element in all the cases. In this way it is assured that the joint failure, for the expected conditions, is produced before the steel reaches its elastic limit [22].

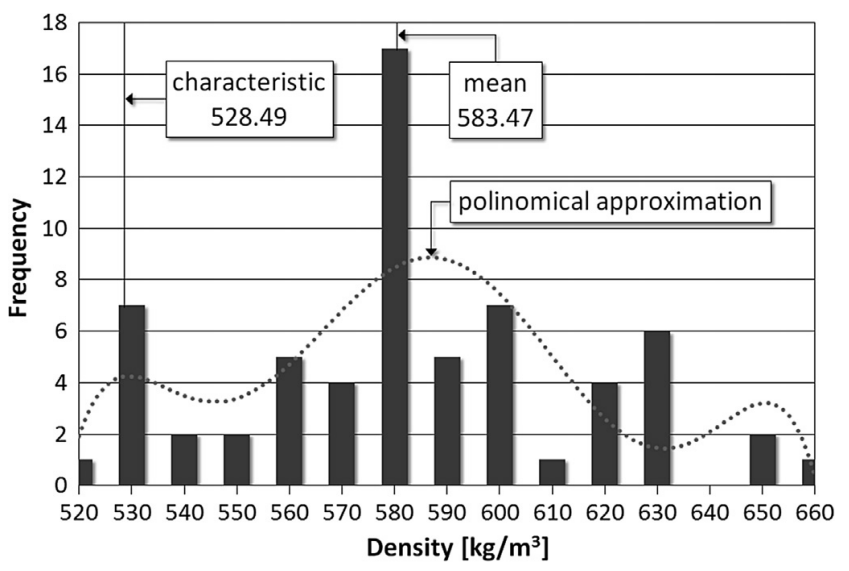

Fig. 1. Distribution of the specimens density.

Epoxy glues were selected as adhesive because they demonstrated the best behavior in different experimental studies [7,14]. In this study it has been used a twocomponent epoxy resin, HILTI HIT-Re 500, specially indicated by the manufacturer (Hilti Corporation) for rebar connections and heavy anchoring. In addition, this product does not require high pressure during its application.

\subsection{Test specimens}

Table 2 shows the initial configuration of the specimens, and presents the numerical values of the associated geometric parameters.

Table 2. Geometric characteristics of the specimens (dimensions expressed in $\mathrm{mm}$ )

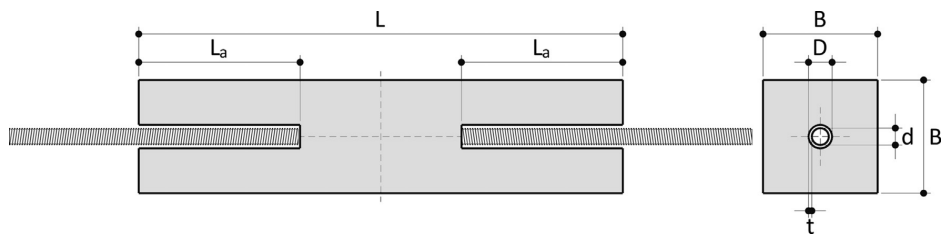

\begin{tabular}{cccccccc}
\hline $\begin{array}{c}\text { Number of } \\
\text { pieces }\end{array}$ & $\begin{array}{c}\text { Length } \\
(\mathrm{L})\end{array}$ & $\begin{array}{c}\text { Cross } \\
\text { section } \\
(\mathrm{BxB})\end{array}$ & $\begin{array}{c}\text { Anchorage } \\
\text { length } \\
(\mathrm{La})\end{array}$ & $\begin{array}{c}\text { Bar } \\
\text { diameter } \\
(\mathrm{d})\end{array}$ & $\begin{array}{c}\text { Slenderness } \\
\lambda=\mathrm{La} / \mathrm{d}\end{array}$ & $\begin{array}{c}\text { Hole } \\
\text { diameter }\end{array}$ & $\begin{array}{c}\text { Adhesive } \\
\text { thickness }\end{array}$ \\
\hline 8 & 180 & $160 \times 160$ & 60 & 12 & 5 & 14 & 1 \\
12 & 360 & $160 \times 160$ & 120 & 12 & 10 & 14 & 1 \\
12 & 500 & $160 \times 160$ & 180 & 12 & 15 & 14 & 1 \\
\hline
\end{tabular}

The cross-section of the timber specimens was established in $160 \times 160 \mathrm{~mm}$. This dimension provides an edge distance much higher to the usual recommendations to avoid the splitting failure $[4,10,22]$. On the other hand, it is necessary to consider that the specimens, once sectioned in half, are going to be submitted to pull-compression test. The proposed section allows to push the bearing zone away from the connection, through a concentric hole in the solid steel plate, avoiding the confinement of the glued area [27]. 
A blind drill of $14 \mathrm{~mm}$ diameter was made in each case. This allows to obtain a glueline with a thickness of $1 \mathrm{~mm}$, in accordance with the manufacturer's recommendations and the experience accumulated by our team in previous campaigns. Moreover, analytical studies indicate that the increase of adhesive consumption is not compensated by a proportional increase of resistance $[2,6,16]$.

The adhesive was injected directly in the drills using a dispenser. Then the bars were introduced manually through a slow rotation. By this way the formation of air bubbles is avoided and a uniform distribution of resin is facilitated. Finally, the leftover adhesive was removed.

\subsection{Climate conditioning}

The main objective of the experimental campaign was to value the incidence of the aging in the resistance of the joints in service conditions. To that end, the previous samples were divided into three sets, according to the type of pre-treatment before the test (table 3$)$. In the case of short anchorage $(60 \mathrm{~mm})$ it was not necessary to apply any conditioning without load due to its rare practical use.

Table 3. Number of pieces for each anchorage length and pre-treatment before the test

\begin{tabular}{ccccc}
\hline \multirow{2}{*}{ Type } & \multicolumn{2}{c}{ Pre-treatment before the test } & \multicolumn{3}{c}{ Anchorage length (mm) } \\
& & 60 & 120 & 180 \\
\hline T1 & Only stabilization in a standardized atmosphere & 4 & 4 & 4 \\
T2 & Artificial accelerated weathering cycles & & 4 & 4 \\
T3 & Artificial accelerated weathering cycles under service load & 4 & 4 & 4 \\
\hline
\end{tabular}

As indicated above, all test specimens were stored in a standardized atmosphere $\left(20^{\circ} \mathrm{C}, 65 \% \mathrm{RH}\right)$ until their stabilization and total curing of the adhesive.

The pieces that were submitted to artificial weathering supported 4 successive cycles, based on the protocol defined in [32] and described in table 4. In each phase the climatic chamber needs some additional time to reach the temperature and relative humidity values which are pretended. This circumstance forces to triple the total duration of the process. (Fig. 2).

Table 4. Artificial accelerated weathering cycles

\begin{tabular}{ccccc}
\hline Cycles & Part & Duration $(\mathrm{h})$ & Temperature $\left({ }^{\circ} \mathrm{C}\right)$ & Relative humidity (\%) \\
\hline \multirow{3}{*}{1 to 4} & A & 24 & $50 \pm 2$ & $87.5 \pm 2.5$ \\
& B & 8 & $10 \pm 2$ & $87.5 \pm 2.5$ \\
& C & 18 & $50 \pm 2$ & $\leq 20.0$ \\
D & 8 & $20 \pm 2$ & $65.0 \pm 5.0$ \\
\hline
\end{tabular}

Additionally, in 2 tests from each series a $3 \mathrm{~mm}$ diameter drill was made with the aim of inserting a type $\mathrm{K}$ thermocouple with a range of measurement of -30 to $+255^{\circ} \mathrm{C}$ (Fig. 3). The hole was sealed by polymer adhesive of high resistance to weathering and UV rays. The register of the thermocouples shows that timber provides a certain connection isolation, so it reaches the temperature of the chamber with a variable gap (Fig. 4). For instance, in the scope outlined in the figure (between 42 and $50^{\circ} \mathrm{C}$ ), the time gap grows from 1.6 to 11.5 hours. 


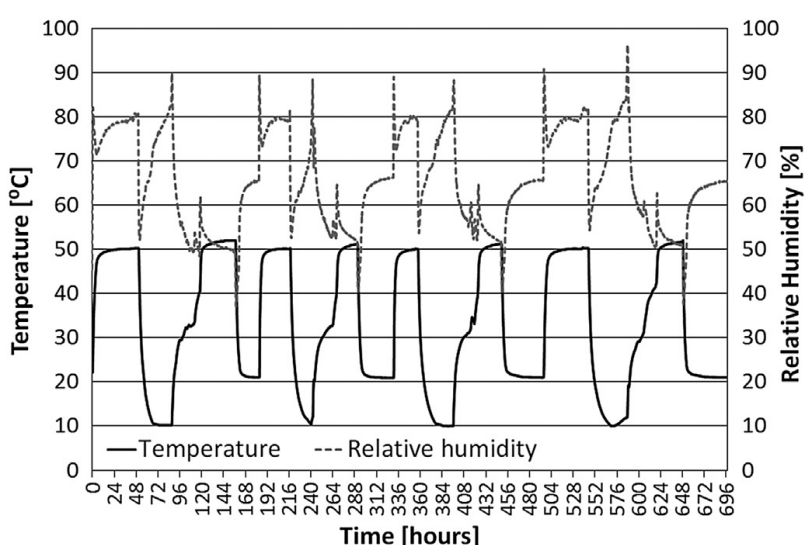

Fig. 2. Conditioning cycles. Measurements of the climatic chamber

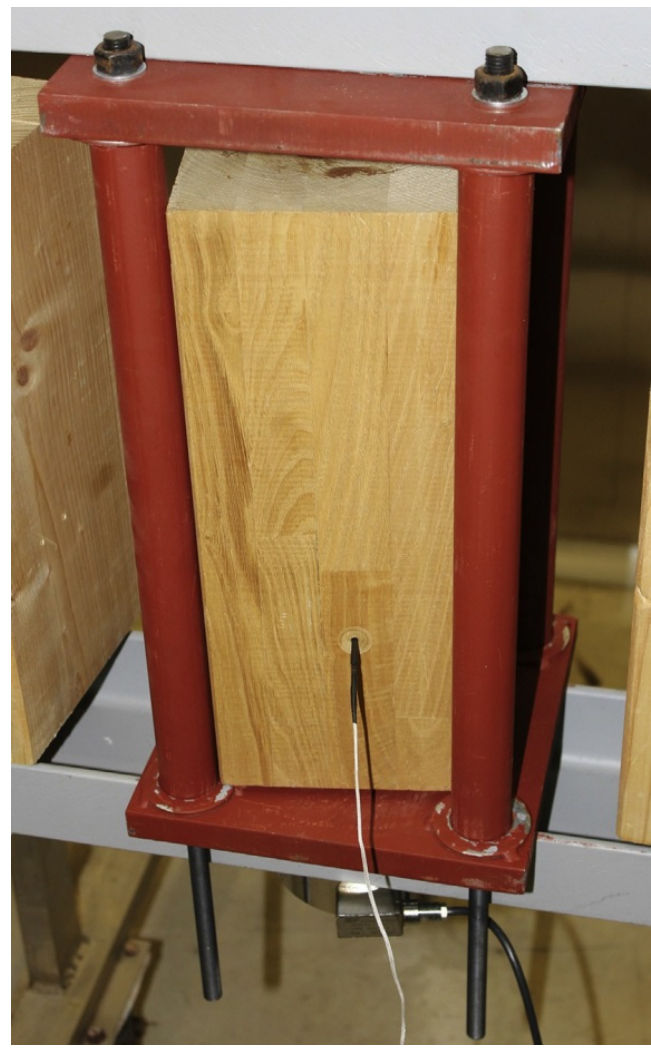

Fig. 3. Thermocouple inserted into the specimen (prior to sealing).

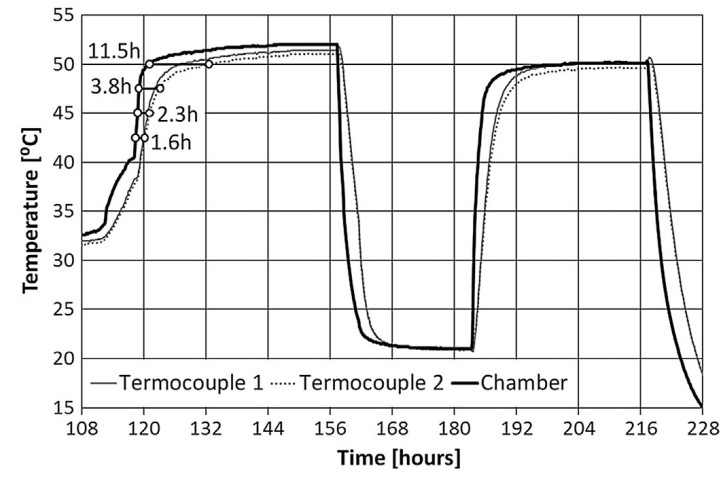

Fig. 4. Thermal cycles. Comparison between climatic chamber and thermocouple measurements. 
As indicated in table 3, for each anchorage length 4 test specimens have been submitted to service load during the aging cycles. This force has been estimated as the $30 \%$ of the characteristic value of the pull-out load, in turn deducted from the tests made on specimens without climate conditioning (table 5). The idea was to maintain the pieces under service load, a number that obviously depends on several factors, such as the proportion between permanent and variable actions or the service class. All out, it has been deducted that the percentage of the 30\% applied, covers the large majority of the usual cases.

Table 5. Estimation of the service load from the pull-out capacity obtained without climate conditioning

\begin{tabular}{cccc}
\hline \multirow{2}{*}{$\begin{array}{c}\text { Anchorage length } \\
(\mathrm{mm})\end{array}$} & Average value $\left(\mathrm{F}_{\mathrm{u}, \mathrm{av}}\right)$ & Characteristic value $\left(\mathrm{F}_{\mathrm{u}, \mathrm{k}}\right)$ & Estimated service load $(\mathrm{kN})$ \\
\hline 60 & 26.34 & 19.97 & 6.0 \\
120 & 53.71 & 41.29 & 12.4 \\
180 & 61.74 & 51.40 & 15.5 \\
\hline
\end{tabular}

In order to keep the test specimens loaded, it was designed a device which is adaptable to the different lengths that are used (figure 5). It consists of 2 steel plates with dimensions of 230x230x20 mm with five holes: the central one allows to place the glued bars and the ones of the ends are used to configure the frame through bars and additional tubes. The tubes are interchangeable to adapt the solution to the different test specimen dimensions. The ensemble is loaded by a nut-ferrule set and a torque wrench. It is also inserted a load cell that allows to control the applied tensioning force.

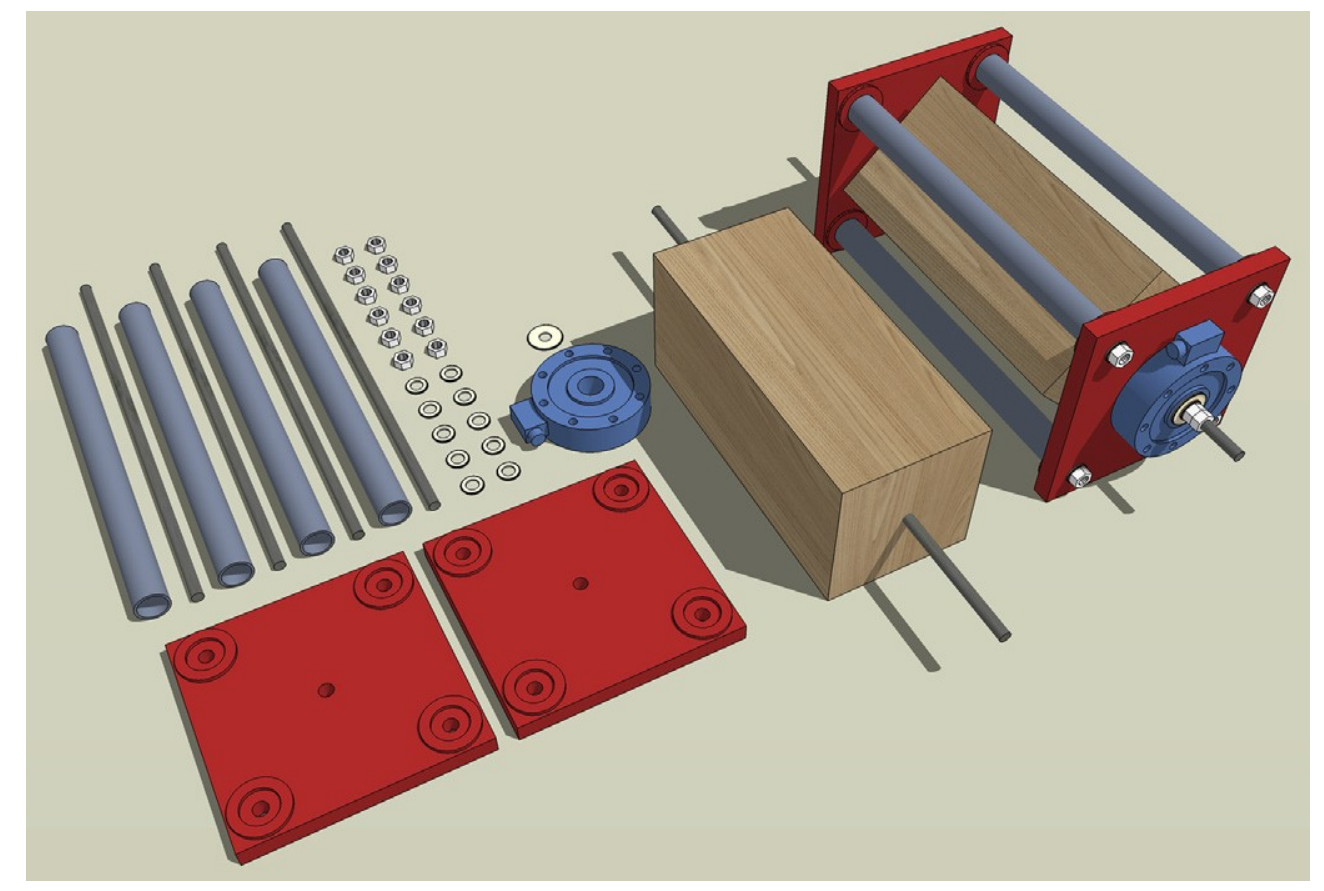

Fig. 5. Load frame.

The arrangement adopted in Fig. 6, with two additional UPN-120 shapes, facilitates the manipulation of the ensemble inside the climatic chamber. 


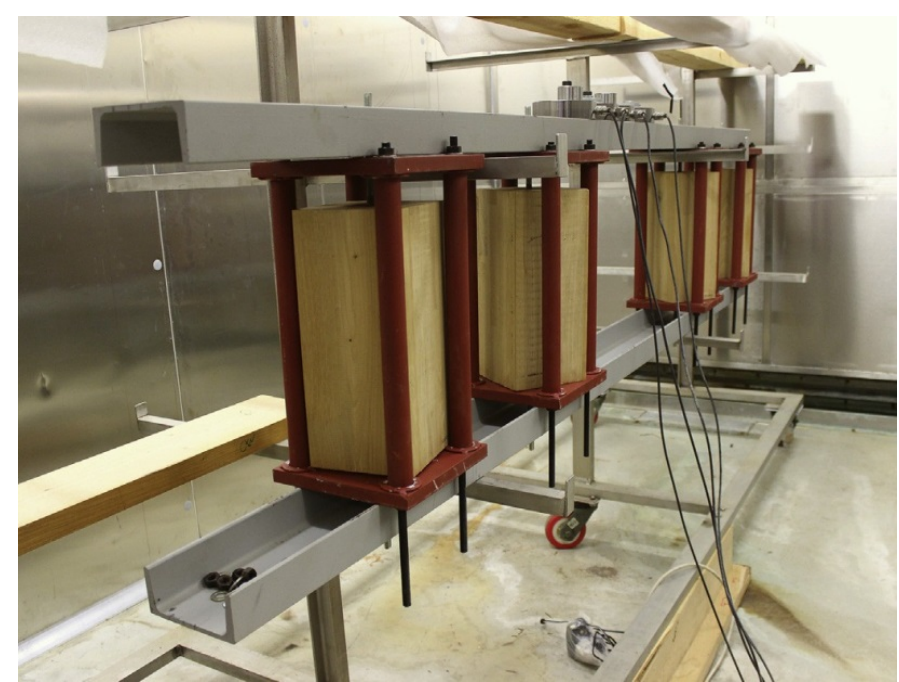

Fig. 6. Group of test specimens in preparation phase inside the climatic chamber.

Once the artificial accelerated weathering cycles end, all the test specimens are stored again in a standardized atmosphere until their stabilization, as a previous step for their test.

\subsection{Test setup}

Once each test specimen is sectioned in half, each one of the obtained fractions was independently submitted to pull-compression test until failure. In this way, the total number of tests (64) doubles the total of manufactured pieces with reference to the initial outline from table 2. Those tests were made in a hydraulic machine Microtest with a maximum capacity of $600 \mathrm{kN}$. Fig. 7 illustrates the test setup. The metal contact plate has a central hole of $80 \mathrm{~mm}$ diameter. Thus the distance from the axis of the bar in tension to its edge itself is superior to three times the diameter of the bar. According to the previous experience of the team with this kind of tests, it is estimated that a significant confinement of the gluing area is not produced.
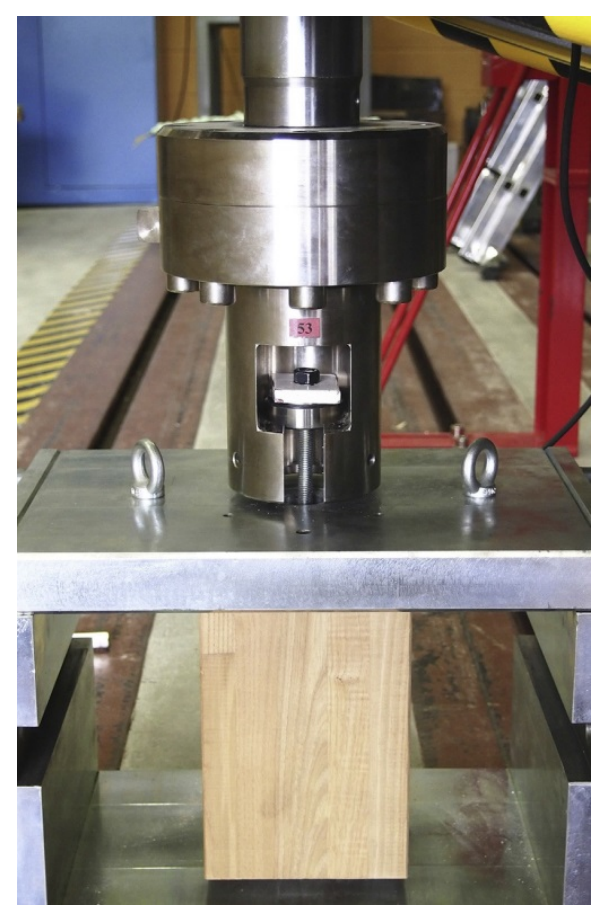

Fig. 7. Test setup. 
Tests were performed with a displacement control in order to satisfy the specifications of [33] for short-term loading tests in timber. The values of load and relative slip were recorded by the electronic data acquisition system during the whole process.

\section{Experimental results and discussion}

In all the cases it has been produced a shear failure in the timber, with the extraction of the rod accompanied by a more or less irregular cylindrical block of timber (Fig. 8). For the tried conditions, this result fully agrees with the previous experimental campaigns conclusions [21].

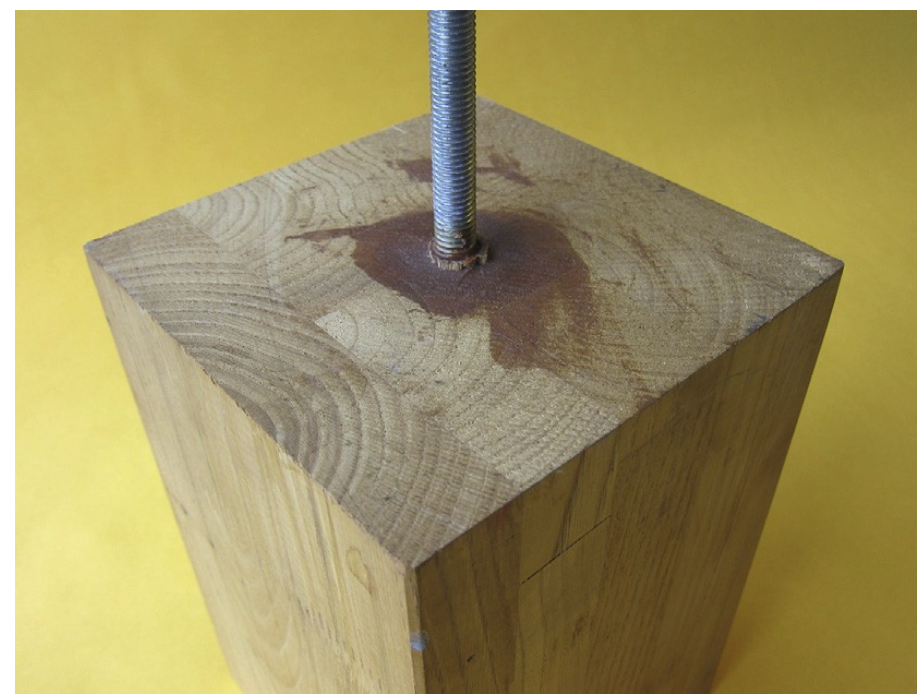

Fig. 8. Failure mode.

The Fig. 9 shows the axial load - relative slip curves obtained with different anchorage lengths. All graphs show an appreciably lineal behaviour. The test specimens that have not been submitted to a previous aging do not present significant stiffness differences. On the other side, the pieces submitted to weathering cycles present a greater deflection than the previous ones. This effect seems to be increased with the anchorage length. To value this issue, it has been determinated in each curve, the slope from the $40 \%$ to the $80 \%$ of the characteristic value of the pull-out capacity $\left(\mathrm{F}_{\mathrm{u}, \mathrm{k}}\right)$ described in the previous table 5 . The reason is that in that scope (outlined as an example in figure 9 for the anchorage of $120 \mathrm{~mm}$ ) all the graphs without exception offer a practically rectilinear trace. Hereafter, it has been calculated the average value for each anchorage length and conditioning process prior to the test. Comparing the test specimens which were not submitted to aging with the ones which were submitted to conditioning cycles, it is observed that the second ones present a loss of stiffness of $4.79 \%$ in the case of short anchorages $(60 \mathrm{~mm})$. That loss is increased until a $12.12 \%$ for $120 \mathrm{~mm}$, and until a $28.0 \%$ for $180 \mathrm{~mm}$. Additionally, it is important to mention that significant differences are not appreciated between the pieces which were or were not submitted to load during the conditioning cycles.

Table 6 gathers the average and characteristic failure load values obtained for each one of the three tried anchorage lengths and for each one of the three conditioning processes considered (according to the definition given on the previous table 3 ). The characteristic values have been obtained in accordance with the European Standard 
EN 14358:2006 [33], using the $\mathrm{k}_{\mathrm{s}}$-factors in order to consider small sample sizes. The complete amount of results obtained in the 64 tests is gathered in figure 10.

Table 6. Number of tests and failure load values $(\mathrm{kN})$

\begin{tabular}{cccccccccc}
\hline \multirow{2}{*}{$\begin{array}{c}\text { Type of treatment } \\
\text { prior to test }\end{array}$} & \multicolumn{1}{c}{ 6o } & \multicolumn{8}{c}{ Anchorage length (mm) } \\
& $\mathrm{n}^{0}$ & $\mathrm{~F}_{\mathrm{u}, \mathrm{va}, 60}$ & $\mathrm{~F}_{\mathrm{u}, \mathrm{k}, 60}$ & $\mathrm{n}^{0}$ & $\mathrm{~F}_{\mathrm{u}, \mathrm{av}, 120}$ & $\mathrm{~F}_{\mathrm{u}, \mathrm{k}, 120}$ & $\mathrm{n}^{0}$ & $\mathrm{~F}_{\mathrm{u}, \mathrm{a}, 180}$ & $\mathrm{~F}_{\mathrm{u}, \mathrm{k}, 180}$ \\
\hline $\mathrm{T} 1$ & 8 & 26.34 & 19.97 & 8 & 53.71 & 41.28 & 8 & 61.74 & 51.39 \\
$\mathrm{~T} 2$ & - & - & - & 8 & 46.23 & 31.13 & 8 & 57.10 & 41.36 \\
$\mathrm{~T} 3$ & 8 & 28.53 & 23.56 & 8 & 50.78 & 35.93 & 8 & 54.90 & 46.00 \\
\hline
\end{tabular}
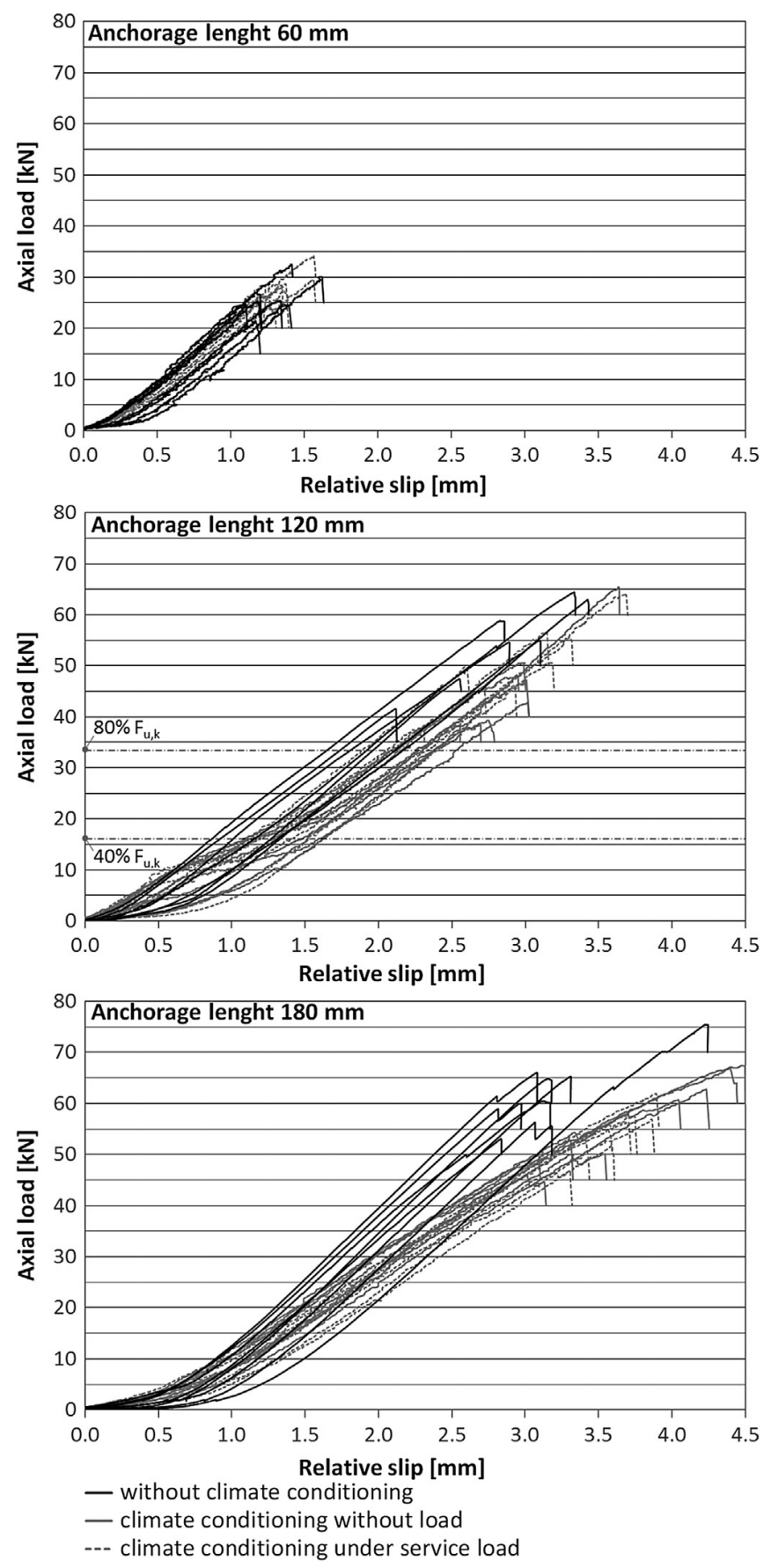

Fig. 9. Axial load - relative slip curves for different anchorage lengths. 
In the case of short anchorages, surprisingly the conditioning cycles under service load lead to small increases of bearing capacity. However, with greater lengths, the cycling treatments produce resistance drops. With $120 \mathrm{~mm}$ of anchorage the average resistance value loses between a $5.46 \%$ (case $\mathrm{T}_{3}$ ) and a $13.93 \%$ (T2). With $180 \mathrm{~mm}$ the loss is established between a 7.52\% (T2) and a 11.08\% (T3). Consequently, the results seem to indicate that the aging cycles can lead, with the usual anchorage lengths, to a loss of bearing capacity. That loss, estimated in characteristic value, could reach, according to the results of the experimental campaign, to a $24.59 \%$.

On the other hand, it is observed that the dreadful results are not necessarily related to a same treatment ( $\mathrm{T}_{2}$ o $\left.\mathrm{T}_{3}\right)$. The conclusions aim that the application of the service load does not necessarily imply a greater loss tan the one produced by the same conditioning without load.

In fact, it does not seem possible to approach a comparative analysis of the obtained results by Custodio et al. [25], due to the fact of using anchorage lengths of only 10 $\mathrm{mm}$. On the contrary, it seems appropriate to gather the studies of Hunger et al. [27] with epoxy adhesives, who have also used bars of $12 \mathrm{~mm}$ of diameter, even though with anchorage lengths of $90 \mathrm{~mm}$ and adhesive thicknesses of $2 \mathrm{~mm}$. In Fig. 10 it has been included the obtained results by these authors with European beech and European ash. Error bars at a 95\% confidence interval (standard climate in continuous line and alternating climate in discontinuous line) are used. The authors consider that the cycles did not lead to degradation of the load carrying capacity. However, it is indeed observed a certain reduction of the minimum of each interval. Therefore, it is observed that the error bar corresponding to a European beech presents a bigger extent in the pieces which were submitted to conditioning cycles.

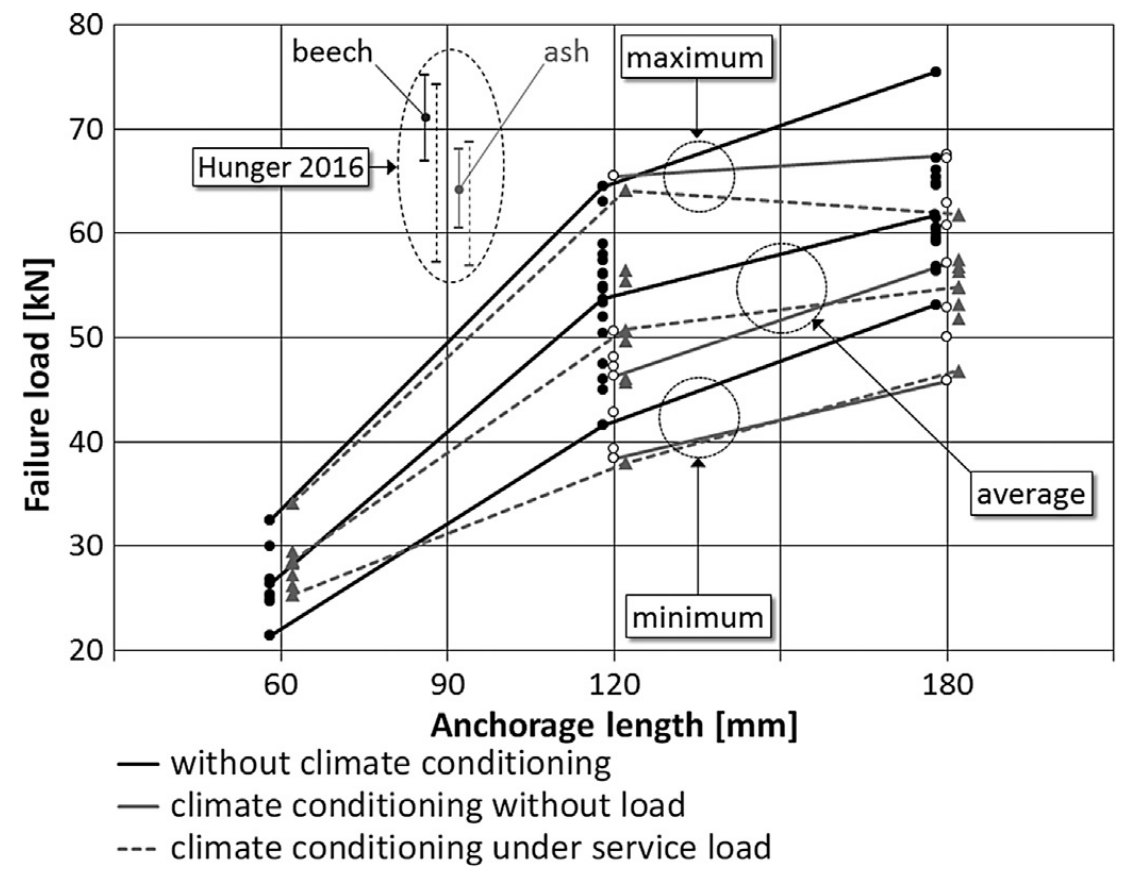

Fig. 10. Comparative graph of values of failure load.

On the other hand, it is observed that the resistance values gathered in that reference are clearly superior to the ones obtained in our experimental campaign. This difference must be related to the use of very different types of timber. In this sense, a relevant fact in order to predict the load capacity of this type of joints is the timber 
density. A greater density always exercises a favourable effect in resistance, even though the different formulations present discrepancies about the way in which this parameter intervenes (Tlustochowicz et al. [17]). The tests of Hunger et al. have been made with average densities of $745 \mathrm{~kg} / \mathrm{m}^{3}$ (European beech) and $642 \mathrm{~kg} / \mathrm{m}^{3}$ (European ash). On the contrary, the pieces analyzed in this paper present an average density clearly inferior (chestnut, $583.47 \mathrm{~kg} / \mathrm{m}^{3}$ ), fact that without any doubt helps to explain the lower resistances obtained. In any case, the dispersion of results that usually accompanies the experimental treatment in this type of joints recommends to increase the number of tests, as well as extending the study to other timber species.

\section{Conclusions}

It has been conducted a total of 64 pull-out tests to determinate the axial strength of joints made with steel rods glued in chestnut timber. It has been used 3 anchorage lengths and 3 environmental conditioning criteria to include durability estimations: stabilization in standardized atmosphere, artificial accelerated weathering cycles, and climate conditioning under service load.

The test constraints have led to an only way of failure that consists on the extraction of the bar accompanied by a wooden cylinder block. The axial load - relative slip curves show an appreciative linear behavior. It is not appreciated significant differences in stiffness between the pieces which have not been submitted to previous aging. On the contrary, the ones which were submitted to climate weathering cycles globally present a greater deflection. This phenomenon seems to deepen with the increase of the anchorage length. Additionally, the fact that the cycles are applied under service load or in a resting state does not seem to have any determinant effect on the loss of stiffness previously commented.

The glued joints have proved a high performance, even in aggressive climate conditions. The epoxy adhesives, like the one here used, present notorious benefits, respecting in any case the recommendations of the manufacturers and particularly the ones related to temperature limits of use. All out, the accelerated aging cycles seem to negatively influence in the pull-out strength of the joints, at least with the usual anchorage lengths in practice. The application of the service load during the cycles cannot be clearly related to a higher or lower loss of resistance.

It exists a limited number of experimental studies in the field of durability of the glued steel joints in hardwood. The results obtained so far advice to increase the number of tests and to include a bigger variety of timber species. Therefore, it is considered to approach natural outdoor weathering with the aim of adapting the conditioning cycles to the real degradation in specific geographical contexts.

\section{References}

[1] Bainbridge R, Mettem C, Harvey K, Ansell M. Bonded-in rod connections for timber structures e development and design methods and test observations. Int $J$ Adhes Adhes 2002; 22(1): 47e59. http://dx.doi.org/10.1016/S0143-7496(01)00036-7.

[2] Senno M, Piazza M, Tomasi R. Axial glued-in steel timber joints e experimental and numerical analysis. Holz Roh Werkst 2004; 62(2):137e46. http:// dx.doi.org/10.1007/s00107-003-0450-1.

[3] Schober KU, Tannert T. Hybrid connections for timber structures. Eur J Wood Prod 2016; 74(3): 369e77. http://dx.doi.org/10.1007/s00107-016-1024-3.

[4] Riberholt H. Glued bolts in glulam. Department of Structural Engineering, Technical University of Denmark; 1986. Series R, no 210. 
[5] Kemmsies M. Comparison of pull-out strengths of 12 adhesives for glued-in rods for timber structures. Swedish National Testing and Research Institute, Building Technology; 1999. SP Report, p. 20.

[6] Broughton JG, Hutchinson AR. Pull-out behaviour of steel rods bonded into timber. Mater Struct 2001; 34: 100e9. http://dx.doi.org/10.1007/BF02481558.

[7] Serrano E. Glued-in rods for timber structures e an experimental study of softening behaviour. Mater Struct 2001; 34(4): 228e34. http://dx.doi.org/10. 1007/BF02480593.

[8] Aicher S, Höfflin L, Wolf M. Influence of specimen geometry on stress distributions in pull-out tests of glued-in steel rods in wood. Otto Graf J 1998; 9: $205 \mathrm{e} 17$.

[9] Blab HJ, Laskewitz B. Glued-in rods for timber structures e GIROD. GIROD Project SMT4CT97-2199, SP Swedish. Boras, Sweden: National Testing and Research Institute; 2002.

[10] Feliglioni L, Lavisci P, Duchanois G, Ciechi MD, Spinelli P. Influence of glue rheology and joint thickness on the strength of bonded-in rods. Holz Roh Werkst 2003; 61(4): 281e7. http://dx.doi.org/10.1007/s00107-003-0387-4.

[11] Steiger R, Gehri E, Widmann R. Pull-out strength of axially loaded steel rods bonded in glulam parallel to the grain. Mater Struct 2006; 40(1): 69e78. http://dx.doi.org/10.1617/s11527-006-111-2.

[12] Rossignon A, Espion B. Experimental assessment of the pull-out strength of single rods bonded in glulam parallel to the grain. Holz Roh Werkst 2008; 66(6): 419e32. http://dx.doi.org/10.1007/s00107-008-0263-3.

[13] Otero D, Estévez J, Martín E, Vázquez JA. Influence of timber density on the axial strength of joints made with glued-in steel rods: an experimental approach. Int J Adhes Adhes 2010; 30(5): 380e5. http://dx.doi.org/10.1016/j. ijadhadh.2010.03.004.

[14] Yeboha D, Taylor S, McPolin D, Gilfillan R, Gilbert S. Behaviour of joints with bonded-in steel bars loaded parallel to the grain of timber elements. Constr Build Mater 2011; 25(5): $2312 \mathrm{e} 7$. http://dx.doi.org/10.1016/j.conbuildmat. 2010.11.026.

[15] Martín E, Estévez J, Otero D. Influence of geometric and mechanical parameters on stress states caused by threaded rods glued in wood. Eur J Wood Prod 2013; 71(2): $259 \mathrm{e} 66$. http://dx.doi.org/10.1007/s00107-013-0678-3.

[16] Tlustochowicz G, Serrano E, Steiger R. State-of-the-art review on timber connections with glued-in steel rods. Mater Struct 2011; 44(5): 997e1020. http://dx.doi.org/10.1617/s11527-0109682-9.

[17] EN 1995-1-1:2004/AC:2006. Eurocode 5: Design of timber structures. Part 1- 1: General. Common rules and rules for buildings: European Committee for Standardization. CEN/TC 250.

[18] Stepinac M, Hunger F, Tomasi R, Serrano E, Rajcic V, Van de Kuilen JWG. Comparison of design rules for glued-in rods and design rule proposal for implementation in European standards. In: Proc of CIB-W18 timber structures, Meeting 46. Vancouver, Canada; 2013.

[19] Ling Z, Yang H, Liu W, Lu W, Zhou D, Wang L. Pull-out strength and bond behaviour of axially load rebar glued-in glulam. Constr Build Mater 2014; 65: 440 9. http://dx.doi.org/10.1016/j.conbuildmat.2014.05.008.

[20] Otero D, Estévez J, Martín E. Glued joints in hardwood timber. Int J Adhes Adhes 2008; 28(8): 457e63. http://dx.doi.org/10.1016/j.ijadhadh.2008.04.008.

[21] Otero D, Estévez J, Martín E. Influence of the geometric and material characteristics on the strength of glued joints made in chestnut timber. Mater Des 2009; 30(4): 1325e32. http://dx.doi.org/10.1016/j.matdes.2008.06.041.

[22] Otero D, Estévez J, Martín E. Experimental analysis of bonding in steel bars glued into chestnut $\begin{array}{lllll}\text { and tali timber. Mater Construct 2010; 60(297): 111e25. } & \text {. }\end{array}$ http://dx.doi.org/10.3989/mc.2010.46708.

[23] Aicher A, Dill-Langer G. Influence of moisture, temperature and load duration on performance of glued-in rods. In: PRO 22: International RILEM symposium on joints in timber structures. Stuttgart: RILEM Publications; 2001. p. 383 e92.

[24] Custódio J, Broughton J, Cruz H. Rehabilitation of timber structures: novel test method to assess the durability of bonded-in rod connections. Mater Struct 2012; 45(1): 1992221. http://dx.doi.org/10.1617/s11527-011-9760-7. 
[25] Lartigau J, Coureau JL, Morel S, Galimard P, Maurin E. Effect of tempertaure on the mechanical performance of glued-in rods in timber structures. Int $J$ Adhes Adhes 2015; 57: 79e84. http://dx.doi.org/10.1016/j.ijadhadh.2014.10.006.

[26] Hunger F, Stepinac M, Rajcic V, Van de Kuilen JWG. Pull-compression tests on glued-in metric thread rods parallel to grain in glulam and laminated veneer lumber of different timber species. Eur J Wood Prod 2016; 74(3): 379e91. http://dx.doi.org/10.1007/s00107-015-1001-2.

[27] EN 301:2013. Adhesives, phenolic and aminoplastic, for loading-bearing timber structures. Classification and performance requirements: European Committee for Standardization. CEN/TC 193.

[28] EN 14080:2013. Timber structures. Glued laminated timber and glued solid timber. Requirements: European Committee for Standardization. CEN/TC 124.

[29] UNE 56531:1977. Physical-mechanical characteristics of wood. Determination of specific weight: AENOR (Spanish Association for Standardisation and Certification). AEN/CTN 56.

[30] EN 1993-1-1:2005/A1:2014. Eurocode 3: Design of steel structures. Part 1-1: General rules and rules for building: European Committee for Standardization. CEN/TC 250.

[31] EN 302-3:2013. Adhesives for load-bearing timber structures. Test methods. Part 3: Determination of the effect of acid damage to wood fibres by temperature and humidity cycling on the transverse tensile strength: European Committee for Standardization. CEN/TC 193.

[32] EN 408:2010+A1:2012. Timber structures. Structural timber and glued laminated timber. Determination of some physical and mechanical proper- ties: European Committee for Standardization. CEN/TC 124 .

[33] EN 14358:2006. Timber structures. Calculation of characteristic 5-percentile values and acceptance criteria for a simple: European Committee for Standardization. CEN/TC 124. 